\title{
A Case of Gastric Heterotopic Pancreatitis Resected by Laparoscopic Surgery
}

\author{
Takatsugu Matsumoto ${ }^{1}$, Nobutaka Tanaka ${ }^{2}$, Motoki Nagai ${ }^{2}$, Daisuke Koike ${ }^{2}$, Yuki \\ Sakuraoka ${ }^{2}$, Keiichi Kubota ${ }^{1}$ \\ ${ }^{1}$ Department of Gastroenterological Surgery, Dokkyo Medical University, Tochigi, Japan \\ ${ }^{2}$ Department of General Surgery, Asahi General Hospital, Chiba, Japan
}

Heterotopic pancreas (HP) is a rare entity which is defined as the presence of pancreatic tissue lacking anatomical and vascular continuity with the pancreas. It is most commonly found along foregut derivatives, such as the stomach, duodenum, and jejunum. It is frequently encountered incidentally in asymptomatic patients, and symptomatic patients are rare and do not exhibit any specific symptoms. Accordingly, HP is difficult to diagnose before surgery. Here we report an unusual case of gastric heterotopic pancreatitis causing gastric outlet obstruction diagnosed preoperatively using endoscopic ultrasonography guided fine needle aspiration cytology. A 21-year-old woman was referred to our hospital because of abdominal pain, nausea, and vomiting. Gastroduodenal endoscopic examination revealed an oval-shaped submucosal tumor in the gastric body. Contrast-enhanced computed tomography (CT) revealed that the tumor had a cystic component and marked perigastric inflammation. Endoscopic ultrasonography (EUS) demonstrated a hypoechoic mass arising from the third to fourth layer of the gastric wall. Pancreatic exocrine glands were detected by EUS-guided fine needle aspiration biopsy. The lesion was diagnosed as gastric heterotopic pancreas with inflammation of the pancreatic tissue. Laparoscopic partial gastrectomy was performed, and the diagnosis was also histologically confirmed. The patient was discharged 5 days after the operation. She has remained healthy and symptom-free during 10 months of follow-up. We experienced a first case of gastric heterotopic pancreatitis which was correctly diagnosed preoperatively and resected by laparoscopic surgery. Partial resection of the heterotopic pancreatic tissue could lead to a good outcome.

Key words: Stomach - Pancreatitis - Laparoscopic surgery 
Table 1 Laboratory data on admission

\begin{tabular}{|c|c|c|c|c|c|}
\hline AST & $(8-38, \mathrm{U} / \mathrm{L})$ & 27 & WBC & $\begin{array}{l}(3200-8500 \\
\left./ \mathrm{mm}^{3}\right)\end{array}$ & $\underline{13700}$ \\
\hline ALT & $(4-44, \mathrm{U} / \mathrm{L})$ & 31 & $\mathrm{Hb}$ & $(11.0-14.8, \mathrm{~g} / \mathrm{dL})$ & $\underline{14.9}$ \\
\hline ALP & $(104-338, \mathrm{U} / \mathrm{L})$ & 191 & Plt & $\left(16.4-35.8,10^{4} / \mu \mathrm{l}\right)$ & $\overline{45.0}$ \\
\hline LDH & $(106-211, \mathrm{U} / \mathrm{L})$ & 199 & & & \\
\hline T-Bil & $(0.1-1.0, \mathrm{mg} / \mathrm{dL})$ & $\underline{1.1}$ & PT & $(70-, \%)$ & 75 \\
\hline $\mathrm{TP}$ & $(6.5-8.1, \mathrm{~g} / \mathrm{dL})$ & $\overline{7.7}$ & APTT & (sec) & 34.1 \\
\hline $\mathrm{Alb}$ & $(3.9-4.9, \mathrm{~g} / \mathrm{dL})$ & 4.9 & $\mathrm{Fbg}$ & $\begin{array}{r}(150-400 \\
\mathrm{mg} / \mathrm{dL})\end{array}$ & 359 \\
\hline $\mathrm{Na}$ & $\begin{array}{l}(135-151 \\
\mathrm{mEq} / \mathrm{L})\end{array}$ & 140 & & & \\
\hline K & $(3.3-4.8, \mathrm{mEq} / \mathrm{L})$ & 3.8 & CRP & $(-0.3, \mathrm{mg} / \mathrm{dL})$ & $\underline{4.57}$ \\
\hline $\mathrm{Cl}$ & $(98-108, \mathrm{mEq} / \mathrm{L})$ & 100 & ESR & $(3-15, \mathrm{~mm} / \mathrm{h})$ & $\underline{26}$ \\
\hline UN & $(7-21, \mathrm{mg} / \mathrm{dL})$ & 11 & & & \\
\hline Cre & $(0.4-0.8, \mathrm{mg} / \mathrm{dL})$ & 0.58 & & & \\
\hline AMY & $(43-116, \mathrm{U} / \mathrm{L})$ & $\underline{122}$ & & & \\
\hline
\end{tabular}

Underlines show abnormal data.

Alb, albumin; ALP, alkaline phosphatase; ALT, alanine aminotransferase; AMY, amylase; APTT, activated partial thromboplastin time; AST, aspartate aminotransferase; Cre, creatinine; CRP, C-reactive protein; ESR, erythrocyte sedimentation rate; $\mathrm{Fbg}$, fibrinogen; $\mathrm{Hb}$, hemoglobin; Plt, platelet; PT-INR, prothrombin time-international normalized ratio; T-Bil, total bilirubin; $\mathrm{TP}$, total protein; $\mathrm{UN}$, urea nitrogen.

$\mathrm{H}$ eterotopic pancreas (HP) is a rare entity defined as the presence of pancreatic tissue outside its normal localization and without anatomic or vascular continuity with the pancreas itself. Other terms such as pancreatic rest, or ectopic, heterotopic, or accessory pancreas, are also used. ${ }^{1}$ It can occur anywhere in the gastrointestinal (GI) tract and its etiology is unknown. In most cases, HP does

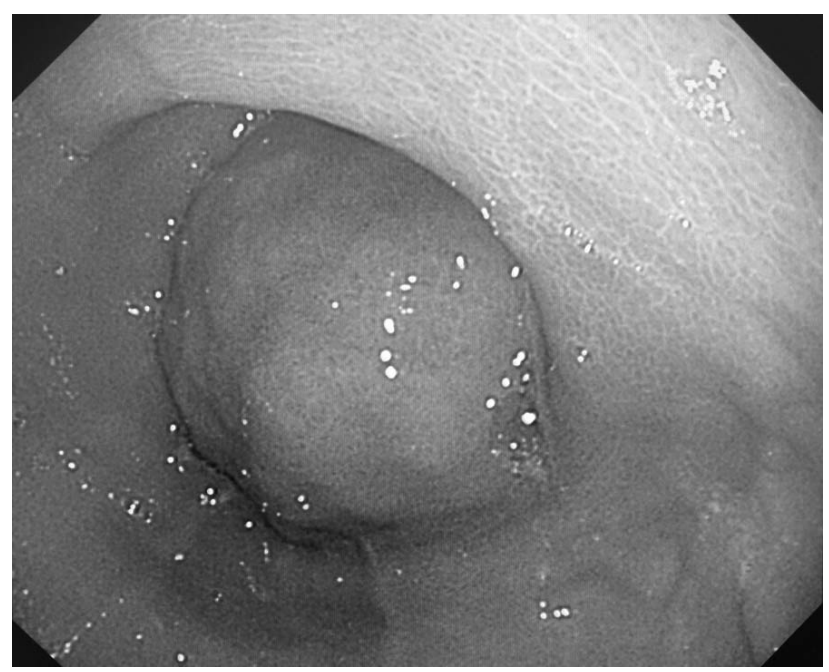

Fig. 1 Large submucosal lesion in the antrum obstructs the gastric outlet.

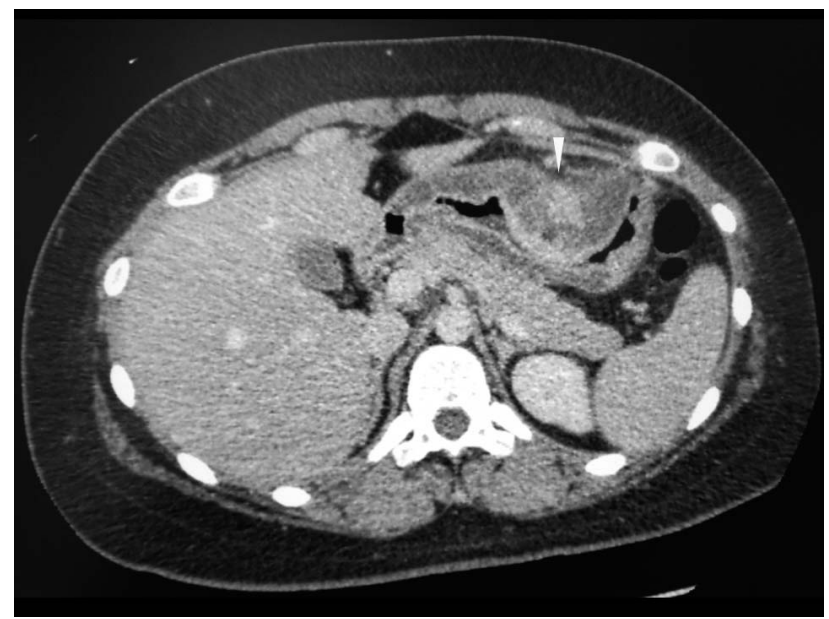

Fig. 2 Contrast-enhanced computed tomography scan demonstrates a large submucosal tumor with marked mucosal edema (arrowhead).

not cause symptoms, but it can occasionally present nausea, vomiting or abdominal pain. ${ }^{2,3}$ Peptic ulceration and upper GI bleeding are rare presentations, ${ }^{4}$ as are malignant degeneration, ${ }^{5,6}$ pancreatitis, and pseudocyst.

Here we report a case of heterotopic pancreatitis causing gastric outlet obstruction which was cor-

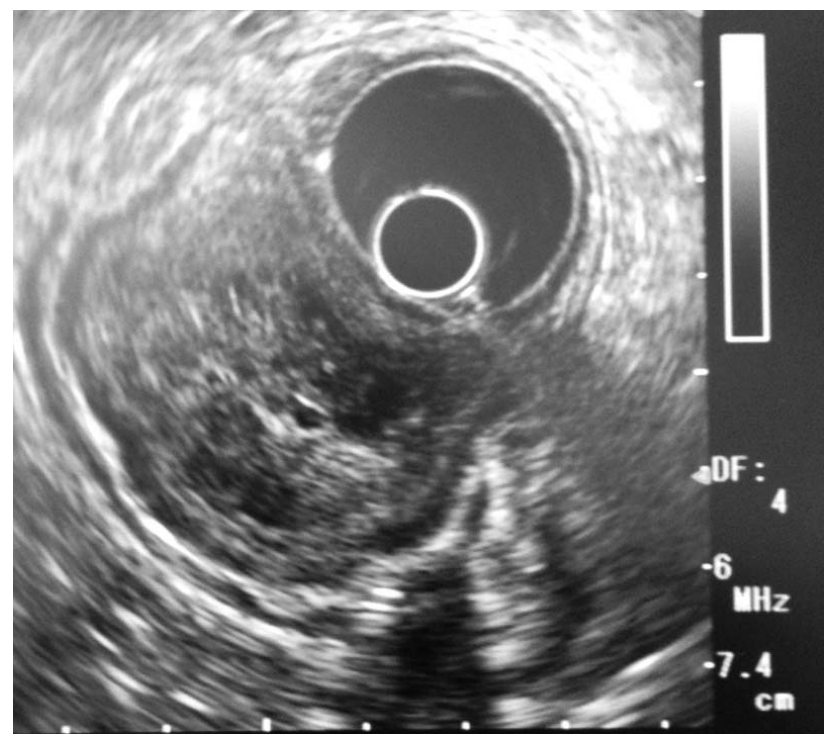

Fig. 3 Endoscopic ultrasonography reveals a tumor with complex low and high echogenicity located in the submucosal and muscle layers (third to fourth layers). 


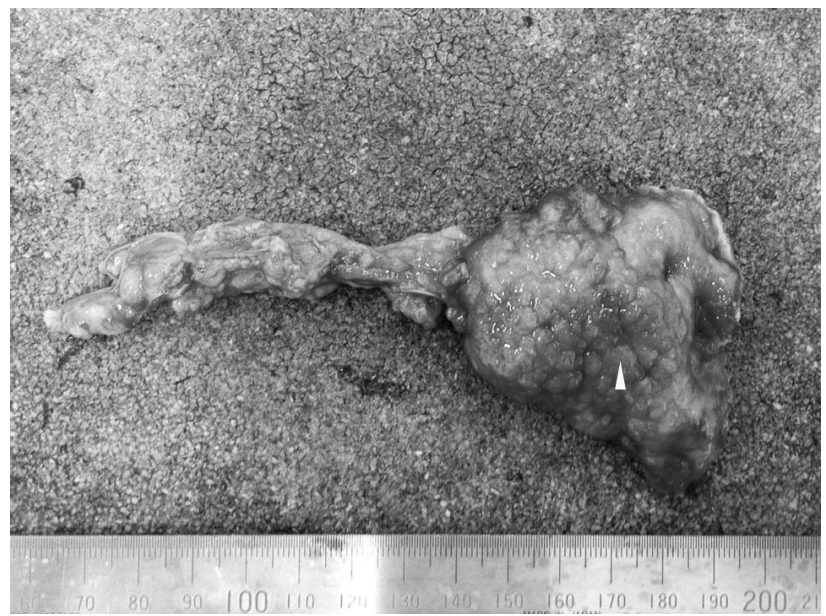

Fig. 4 Resected gastric wall with omental tissue. The mucosa is markedly edematous. A central indentation is evident on the submucosal tumor (arrowhead).

rectly diagnosed preoperatively and resected by laparoscopic surgery.

\section{Case Report}

A 21-year-old woman was admitted to our hospital complaining of epigastric pain and recurrent vomiting after meals. Her medical history was unremarkable except for chlamydial cervicitis. Physical examination demonstrated epigastric tenderness but no rebound pain, and her bowel sounds were slightly weak.

Hematologic examination revealed a slightly elevated serum amylase level (Table 1). Gastroscopy demonstrated a large submucosal tumor located mainly at the gastric body, where the mucosa appeared scaly (Fig. 1). Contrast-enhanced computed tomography (CT) revealed a large submucosal tumor with marked mucosal edema (Fig. 2). Endoscopic ultrasonography (EUS) revealed a lesion $3 \mathrm{~cm}$ in diameter surrounded by an area with complex low and high echogenicity, located within either the third or fourth echo-layer (Fig. 3).

An EUS-guided fine-needle aspiration sample revealed that the tumor was heterotopic pancreas. Therefore we considered that the patient's abdominal pain was due to gastritis caused by heterotopic pancreatitis, and performed laparoscopic partial gastrectomy.

The gastric wall and the omentum were extremely edematous, and bled easily. As the tumor was poorly marginated at the serous surface, we cut

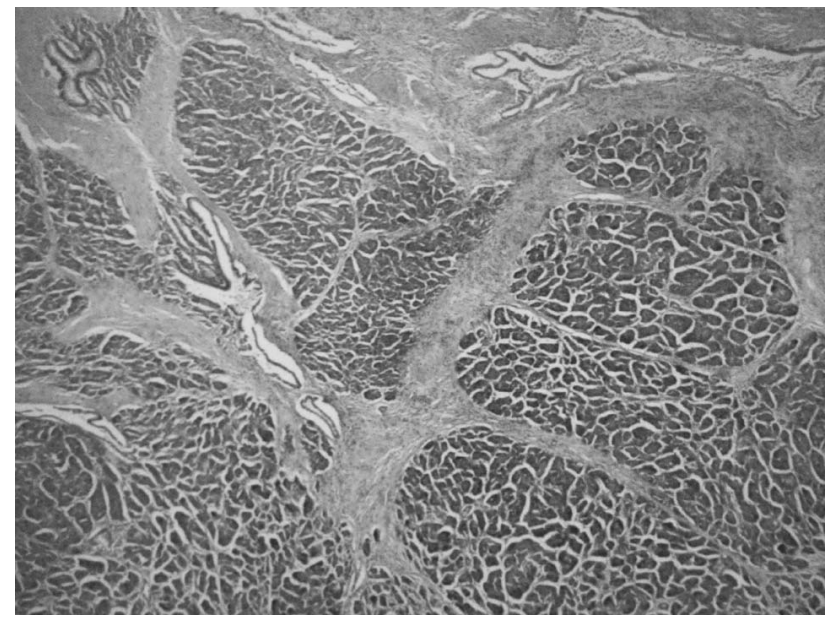

Fig. 5 Histologic features of the gastric submucosal tumor stained with HE (low-power field). Pancreatic acinar cells, ducts, and islets of Langerhans are visible in the gastric submucosa.

open the stomach body to decide the resection line on the basis of the evident mucosal change. The resected mass was present in the submucosa. It was whitish and lobulated, measuring $2.6 \mathrm{~cm} \times 2.0 \mathrm{~cm}$ in diameter, and the resection margins were negative. The mucosa was markedly edematous, and a central indentation was evident at the top of the submucosal tumor (Fig. 4).

Histologic examination revealed that the tumor contained pancreatic acinar cells, ducts, and islets of Langerhans (Fig. 5), thus the patient was diagnosed with Heinrich type I heterotopic pancreatitis.

The postoperative course was uneventful, and the patient was discharged 5 days after the operation. And the patient has remained healthy and symptom-free during 10 months of follow-up.

\section{Discussion}

HP is relatively rare, and is defined as pancreatic tissue in an abnormal location, having no contact with the normal pancreas and possessing its own ductal system and blood supply. HP is a rare entity and is reportedly present in 0.5 to $13 \%$ of autopsy cases, mainly in the stomach. ${ }^{6,7}$

Gastric heterotopic pancreas (GHP) is usually asymptomatic, but depending on its location and size, it may produce clinical symptoms, most commonly vomiting or abdominal pain. ${ }^{1,8}$ A significant correlation between the size of the lesion and the presence of symptoms has been reported., Armstrong et al have stated that lesions exceeding 


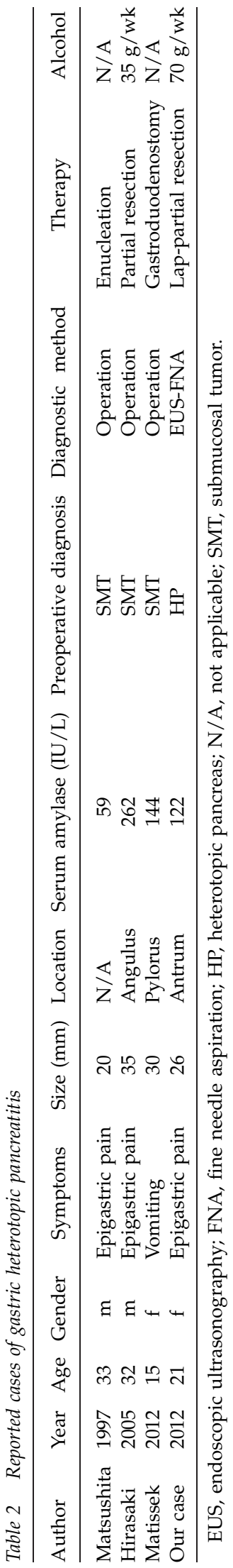

$15 \mathrm{~mm}$ in diameter are more likely to be of clinical significance. $^{3}$

A MEDLINE search of the English literature revealed 4 cases of acute pancreatitis occurring in GHP in the last 30 years, including our case $\mathrm{1}^{10-12}$ (Table 2). Epigastric pain was reported in 3 cases. Two were male and 2 were female. Median age was 26.5 years old.

The diagnosis of GHP is difficult as there are no specific diagnostic methods. ${ }^{1-3,6}$ Indeed, other 3 cases were diagnosed postoperatively. We could reach pathologic diagnosis preoperatively using endoscopic ultrasonography guided fine needle aspiration cytology (EUS-FNA).

All cases were treated by surgical resection, and only 1 case went through laparoscopic procedure (our case). The prognosis after surgery is generally favorable. Complete symptom remission was achieved in all reported cases, including our case.

Surgical treatment is recommended for symptomatic GHP, as it can reduce the associated symptoms. ${ }^{1,8,9}$ There is some debate as to whether GHP should be treated if the symptoms are absent. ${ }^{8}$ Excision should be considered in cases that exceed $1.5 \mathrm{~cm}$ in diameter to prevent any symptoms developing, or if the lesion is increasing in size or has endocrine function resembling insulinoma.

Partial resection of the stomach for submucosal tumor is preferable for preservation of gastric function. Recently, laparoscopic surgery has been widely accepted for GHP. ${ }^{1,13}$ However, it is sometimes difficult to marginate the tumor from the serosal surface, ${ }^{14,15}$ especially as with our case, which is accompanied by pancreatitis. There is no report of heterotopic pancreatitis resected by laparoscopic surgery. In such case, mini-laparotomy (laparoscopy-assisted gastrectomy) or intraoperative GF may be necessary in order to decide the resection line. ${ }^{14}$ We determined cutter line by opening the stomach body and inspection of the mucosal side. As is the case for other submucosal lesions, use of intraoperative gastroendoscopy and laparoscopy may become more common.

\section{Conclusion}

We experienced a first case of gastric heterotopic pancreatitis, which was successfully diagnosed preoperatively and resected by laparoscopic surgery. Partial resection of the heterotopic pancreatic tissue could lead to a good outcome. 


\section{Acknowledgments}

We have no conflict of interest to declare. We received no funding/grant support for this study.

\section{References}

1. Ormarsson OT, Gudmundsdottir I, Marvik R. Diagnosis and treatment of gastric heterotopic pancreas. World J Surg 2006; 30(9):1682-1689

2. Hsu SD, Chan DC, Hsieh HF, Chen TW, Yu JC, Chou SJ. Ectopic pancreas presenting as ampulla of Vater tumor. Am J Surg 2008;195(4):498-500

3. Armstrong CP, King PM, Dixon JM, Macleod IB. The clinical significance of heterotopic pancreas in the gastrointestinal tract. Br J Surg 1981;68(6):384-387

4. Ueno S, Ishida H, Hayashi A, Kamagata S, Morikawa M. Heterotopic pancreas as a rare cause of gastrointestinal hemorrhage in the newborn: report of a case. Surg Today 1993;23(3):269-272

5. Cardenas CM, Dominguez I, Campuzano M, Bezaury P, Iniguez-Rodriguez M, Gamboa-Dominguez A et al. Malignant insulinoma arising from intrasplenic heterotopic pancreas. $J$ Pancreas 2009;10(3):321-323

6. Tanaka K, Tsunoda T, Eto T, Yamada M, Tajima Y, Shimogama $\mathrm{H}$ et al. Diagnosis and management of heterotopic pancreas. Int Surg 1993;78(1):32-35

7. De Castro Barbosa JJ, Dockerty MB, Waugh JM. Pancreatic heterotopia: review of the literature and report of 41 authenticated surgical cases, of which 25 were clinically significant. Surg Gynecol Obstet 1946;82:527-542

8. Eisenberger CF, Gocht A, Knoefel WT, Busch CB, Peiper M, Kutup A et al. Heterotopic pancreas-clinical presentation and pathology with review of the literature. Hepatogastroenterology 2004;51(57):854-858

9. Martinez NS, Morlock CG, Dockerty MB, Waugh JM, Weber HM. Heterotopic pancreatic tissue involving the stomach. Ann Surg 1958;147(1):1-12

10. Hirasaki S, Tanimizu M, Moriwaki T, Nasu J. Acute pancreatitis occurring in gastric aberrant pancreas treated with surgery and proved by histological examination. Intern Med 2005;44(11):1169-1173

11. Matsushita M, Hajiro K, Takakuwa H. Acute pancreatitis occurring in gastric aberrant pancreas accompanied by paralytic ileus. Am J Gastroenterol 1997;92(11):2121-2122

12. Matissek C, Grundhuber H, Steinborn M, Hosie S. Gastric outlet obstruction caused by heterotopic pancreatitis. Eur J Pediatr Surg 2012;22(2):165-167

13. Hsu SD, Wu HS, Kuo CL, Lee YT. Robotic-assisted laparoscopic resection of ectopic pancreas in the posterior wall of gastric high body: case report and review of the literature. World J Gastroenterol 2005;11(48):7694-7696

14. Hiki N, Yamamoto Y, Fukunaga T, Yamaguchi T, Nunobe S, Tokunaga $\mathrm{M}$ et al. Laparoscopic and endoscopic cooperative surgery for gastrointestinal stromal tumor dissection. Surg Endosc 2008;22(7):1729-1735

15. Hyung WJ, Lim JS, Cheong JH, Kim J, Choi SH, Noh SH. Laparoscopic resection of a huge intraluminal gastric submucosal tumor located in the anterior wall: eversion method. Journal Surg Oncol 2005;89(2):95-98

(C) 2015 Matsumoto et al.; licensee The International College of Surgeons. This is an Open Access article distributed under the terms of the Creative Commons Attribution Non-commercial License which permits use, distribution, and reproduction in any medium, provided the original work is properly cited, the use is non-commercial and is otherwise in compliance with the license. See: http://creativecommons.org/licenses/by-nc/3.0 